\title{
FRACTIONAL DYNAMICS IN JAPANESE FINANCIAL TIME SERIES \&
}

\author{
John T. Barkoulas \\ Department of Economics \\ Boston College \\ Chestnut Hill, MA 02167 USA \\ Christopher F. Baum \\ Department of Economics \\ Boston College \\ Chestnut Hill, MA 02167 USA
}

\begin{abstract}
Using the spectral regression and Gaussian semiparametric methods of estimating the long-memory parameter, we test for fractional dynamic behavior in a number of important Japanese financial time series: spot exchange rates, forward exchange rates, stock prices, currency forward premia, Euroyen deposit rates, and the Euroyen term premium. Stochastic long memory is established as a feature of the currency forward premia, Euroyen deposit rates, and Euroyen term premium series. The martingale model cannot be rejected for the spot, forward, and stock price series.
\end{abstract}

JEL codes: C22, G12

Keywords: Time series, long memory, spectral regression, Gaussian semiparametric method

\footnotetext{
$\S$ We acknowledge the contributions of two anonymous referees and the competent research assistance of Patrick Franke. The standard disclaimer applies. Corresponding author: Christopher F. Baum, Department of Economics, Boston College, Chestnut Hill, MA 02167 USA, Tel: 617-552-3673, Fax 617-5522308,email: baum@bc.edu.
} 


\section{FRACTIONAL DYNAMICS IN JAPANESE FINANCIAL TIME SERIES}

\section{Introduction}

The potential presence of stochastic long memory in economic and financial time series has been an important subject of both theoretical and empirical research. The long-memory, or long-term dependence, property describes the high-order correlation structure of a series. If a series exhibits long memory, there is persistent temporal dependence between observations widely separated in time. Such series exhibit hyperbolically decaying autocorrelations and low-frequency spectral distributions. Fractionally integrated processes can give rise to long memory (Mandelbrot (1977), Granger and Joyeux (1980), Hosking (1981)). On the other hand, the short-memory, or short-term dependence, property describes the low-order correlation structure of a series. Short-memory series are typified by quickly declining autocorrelations and high-frequency spectral distributions. Standard autoregressive moving average processes cannot exhibit long-term (low-frequency) dependence as they can only describe the short-run (high-frequency) behavior of a time series.

The presence of fractional structure in asset returns raises a number of theoretical and empirical issues. First, as long memory represents a special form of nonlinear dynamics, it calls into question linear modeling and invites the development of nonlinear pricing models at the theoretical level to account for longmemory behavior. Mandelbrot (1971) observes that in the presence of long memory, the arrival of new market information cannot be fully arbitraged away and martingale models of asset prices cannot be obtained from arbitrage. Second, pricing 
derivative securities with martingale methods may not be appropriate if the underlying continuous stochastic processes exhibit long memory. Third, statistical inferences concerning asset pricing models based on standard testing procedures may not be appropriate in the presence of long-memory series (Yajima (1985)). Finally, as long memory creates nonlinear dependence in the first moment of the distribution and generates a potentially predictable component in the series dynamics, its presence casts doubt on the weak form of the market efficiency hypothesis. The price of an asset determined in an efficient market should follow a martingale process in which each price change is unaffected by its predecessor and has no memory. The presence of long memory in asset returns implies significant autocorrelations between distant observations. Consequently, past returns can help predict future returns, and the possibility of consistent speculative profits arises.

Given the implications of long memory for the theory and practice of financial economics, a number of studies have investigated the issue of persistence in financial asset returns. Using the rescaled-range (R/S) method, Greene and Fielitz (1977) report long memory in daily stock returns series. This result is overturned by Lo (1991) via the development and implementation of the more appropriate modified R/S method. Absence of long memory in stock returns is also reported by Aydogan and Booth (1988), Cheung, Lai, and Lai (1993), Cheung and Lai (1995), Crato (1994), and Barkoulas and Baum (1996). Booth, Kaen, and Koveos (1982) and Cheung (1993) report long-memory evidence in spot exchange rates. Helms, Kaen, and Rosenman (1984), Cheung and Lai (1993), Fang, Lai, and Lai (1994), and Barkoulas, Labys, and Onochie $(1997 \mathrm{a}, \mathrm{b})$ report that stochastic long memory may be a feature of some spot and futures foreign currency rates and commodity prices. ${ }^{1}$

\footnotetext{
1 See Baillie (1996) for a survey of fractional integration methods and other applications in economics and finance.
} 
In this study we investigate the presence of fractional dynamics in several important price series of Japanese financial assets. In particular, we analyze the longterm dynamic behavior of spot and forward exchange rates of the Japanese yen vis-àvis major currencies, stock prices, currency forward premia, and rates for 3- and 6month Euroyen deposits and the corresponding term premium series. The longmemory parameter is estimated via the spectral regression and Gaussian semiparametric methods. We find substantial evidence of long-range dependence in the forward premia series, the Euroyen deposit rates, and their term premium. The empirical evidence is consistent with the martingale model for the spot and forward currency rates as well as for the Japanese stock prices.

The paper is constructed as follows. Section 2 presents the fractional integration testing methodologies. Data and empirical estimates are discussed in Section 3. We conclude in Section 4 with a summary of our results.

\section{Fractional Integration Tests}

The model of an autoregressive fractionally integrated moving average process of order $(p, d, q)$, denoted by $\operatorname{ARFIMA}(p, d, q)$, with mean $\mu$, may be written using operator notation as

$$
\Phi(L)(1-L)^{d}\left(y_{t}-\mu\right)=\Theta(L) u_{t}, \quad u_{t} \sim \text { i.i.d. }\left(0, \sigma_{u}^{2}\right)
$$

where $L$ is the backward-shift operator, $\Phi(L)=1-\phi_{1} L-\ldots-\phi_{p} L^{p}, \Theta(L)=1+\vartheta_{1} L+$ $\ldots+\vartheta_{q} L^{q}$, and $(1-L)^{d}$ is the fractional differencing operator defined by 


$$
(1-L)^{d}=\sum_{k=0}^{\infty} \frac{\Gamma(k-d) L^{k}}{\Gamma(-d) \Gamma(k+1)}
$$

with $\Gamma(\cdot)$ denoting the gamma function. The parameter $d$ is allowed to assume any real value. The arbitrary restriction of $d$ to integer values gives rise to the standard autoregressive integrated moving average (ARIMA) model. The stochastic process $y_{t}$ is both stationary and invertible if all roots of $\Phi(L)$ and $\Theta(L)$ lie outside the unit circle and $|d|<0.5$. The process is nonstationary for $d \geq 0.5$, as it possesses infinite variance, i.e. see Granger and Joyeux (1980). Assuming that $d \in(0,0.5)$ and $d \neq 0$, Hosking (1981) showed that the correlation function, $\rho(\cdot)$, of an ARFIMA process is proportional to $k^{2 d-1}$ as $k \rightarrow \infty$. Consequently, the autocorrelations of the ARFIMA process decay hyperbolically to zero as $k \rightarrow \infty$ which is contrary to the faster, geometric decay of a stationary ARMA process. For $d \in(0,0.5), \sum_{j=-n}^{n}|\rho(j)|$ diverges as $n \rightarrow \infty$, and the ARFIMA process is said to exhibit long memory, or long-range positive dependence. The process is said to exhibit intermediate memory (antipersistence), or long-range negative dependence, for $d \in(-0.5,0)$. The process exhibits short memory for $d=0$, corresponding to stationary and invertible ARMA modeling. For $d \in[0.5,1)$ the process is mean reverting, even though it is not covariance stationary, as there is no long-run impact of an innovation on future values of the process.

We estimate the long-memory parameter using the spectral regression and Gaussian semiparametric methods, which we present next. 


\section{A. The Spectral Regression Method}

Geweke and Porter-Hudak (1983) suggest a semiparametric procedure to obtain an estimate of the fractional differencing parameter $d$ based on the slope of the spectral density function around the angular frequency $\xi=0$. More specifically, let $I(\xi)$ be the periodogram of $\mathbf{y}$ at frequency $\xi$ defined by

$$
I(\xi)=\frac{1}{2 \pi T}\left|\sum_{t=1}^{T} e^{i t \xi}\left(y_{t}-\bar{y}\right)\right|^{2}
$$

Then the spectral regression is defined by

$$
\ln \left\{I\left(\xi_{\lambda}\right)\right\}=\beta_{0}+\beta_{1} \ln \left\{4 \sin ^{2}\left(\frac{\xi_{\lambda}}{2}\right)\right\}+\eta_{\lambda}, \quad \lambda=1, \ldots, v
$$

where $\xi_{\lambda}=\frac{2 \pi \lambda}{T}(\lambda=0, \ldots, T-1)$ denotes the Fourier frequencies of the sample, $T$ is the number of observations, and $v=g(T) \ll T$ is the number of Fourier frequencies included in the spectral regression.

Assuming that $\lim _{T \rightarrow \infty} g(T)=\infty, \lim _{T \rightarrow \infty}\{g(T) / T\}=0$, and $\lim _{T \rightarrow \infty} \ln (T)^{2} / g(T)=0$, the negative of the OLS estimate of the slope coefficient in (4) provides an estimate of $d$. The properties of the regression method depend on the asymptotic distribution of the normalized periodogram, the derivation of which is not straightforward. Geweke and Porter-Hudak (1983) prove consistency and asymptotic normality for $d<0$, while Robinson (1995a) proves consistency and asymptotic normality for $d \in(0,0.5)$ in the case of Gaussian ARMA innovations in (1). 


\section{B. The Gaussian Semiparametric Method}

Robinson (1995b) proposes a Gaussian semiparametric estimate, referred to as the GS estimate hereafter, of the self-similarity parameter $H$, which is not defined in closed form. It is assumed that the spectral density of the time series, denoted by $f(\cdot)$, behaves as

$$
f(\xi) \sim G \xi^{1-2 H} \text { as } \xi \rightarrow 0^{+}
$$

for $G \in(0, \infty)$ and $H \in(0,1)$. The self-similarity parameter $H$ relates to the longmemory parameter $d$ by $H=d+1 / 2$. The estimate for $H$, denoted by $\hat{H}$, is obtained through minimization of the function

$$
R(H)=\ln \hat{G}(H)-(2 H-1) \frac{1}{v} \sum_{\lambda=1}^{v} \ln \xi_{\lambda}
$$

with respect to $H$, where $\hat{G}(H)=\frac{1}{v} \sum_{\lambda=1}^{v} \xi_{\lambda}^{2 H-1} I\left(\xi_{\lambda}\right)$. The discrete averaging is carried out over the neighborhood of zero frequency and, in asymptotic theory, $v$ is assumed to tend to infinity much more slowly than does $T$. The GS estimator has several advantages over the spectral regression estimator and its variants. It is consistent under mild conditions and, under somewhat stronger conditions, it is asymptotically normal and more efficient. Gaussianity is nowhere assumed in the asymptotic theory. The GS estimator is $v^{1 / 2}$-consistent and the variance of the limiting distribution is free of nuisance parameters and equals $\frac{1}{4 v}$. 


\section{Data and Empirical Estimates}

The data set consists of weekly spot and 3-month forward exchange rates, monthly values of the Japanese stock index, and daily Eurocurrency deposit rates for the Japanese yen. We analyze cross-currency spot and forward rates of the Japanese yen with respect to the U.S. dollar, Canadian dollar, Deutsche mark, British pound, French franc, Swiss franc, Netherlands guilder, and Italian lira from 01/07/1974 to $01 / 27 / 1997$ for a total of 1,204 weekly observations. These rates represent Wednesday noon-time bid prices from the New York foreign exchange market and were obtained from the Federal Reserve Board of Governors. Monthly values for the Japanese stock index span the period 1960:1 to 1996:5 and were obtained from Citibase. The deposit rates are daily 3-month and 6-month rates on Eurocurrency deposits denominated in Japanese yen (Euroyen rates) from $01 / 01 / 85$ to $02 / 08 / 94$ for a total of 2,300 observations. These quotes represent bid rates at the close of trading in the London market and were obtained from Data Resources, Inc.

In estimating the fractional exponent, a choice has to be made with respect to the number of low-frequency periodogram ordinates used. Improper inclusion of medium- or high-frequency periodogram ordinates will bias the estimate of $d$; at the same time too small a regression sample will increase the sampling variability of the estimates. We report $d$ estimates for $T^{0.50}$ and $T^{0.55} .^{2}$

Table 1 reports the spectral regression and GS estimates of the fractional differencing parameter $d$ and the test results for the spot and forward returns series as well as for the stock returns series (the returns series are logarithmic differences of the original series). For both spot and forward returns series, the empirical estimates suggest the absence of long memory, with the possible exception of the French

2 We check the sensitivity of our results to the choice of the estimation sample size $v$ by producing $d$ estimates for other plausible choices for $v$. The results to follow are robust to the choice of $v$. 
franc/yen rate. The Japanese stock returns series is clearly a short-memory process. The evidence for foreign exchange and stock returns series is consistent with the dictum of the weak form of capital market efficiency, which implies unpredictability of future returns based on historical returns.

We subsequently investigate the long-term correlation structure of the forward premia series. The forward premium is defined as the difference between the (natural) logarithm of the forward foreign currency rate at time $t$ of a forward contract with delivery date $t+k$ ( $k$ corresponds to a 3-month period in our case), denoted by $f(t, t+k)$, and the logarithm of the spot rate at time $t$, denoted by $s(t)$. Table 2 reports the long-memory estimates for the first-differenced forward premia series. The fractional exponent estimates for the levels of the forward premia series lie outside the stationarity boundary of 0.5 . Although these series have infinite variances, their finite cumulative impulse responses cause them to be meanreverting processes. A shock to the forward premia series exhibits significant persistence but it eventually dissipates at a slow hyperbolic rate of decay. The strong autocorrelation in the forward premia series is attributed to the strong autocorrelation in the interest-rate differential (see Brenner and Kroner (1995) for theoretical arguments and Akella and Patel (1991) for empirical evidence). ${ }^{3}$ Similar evidence of long memory is also found in Baillie and Bollerslev (1994) for the U.S.dollar forward premia series for the Canadian dollar, Deutsche mark, and British pound.

Finally, we test for stochastic long memory in 3-month and 6-month Euroyen rates and the corresponding term premium series (the 6-month rate minus the 3month rate). The fractional integration tests are applied to the first-differenced series. As Table 3 reports, consistent evidence of long memory is obtained for the Euroyen

\footnotetext{
3 The covered interest parity condition states that $f(t, t+k)-s(t)=i(t)-i^{*}(t)$, where $i(t)$ and $i^{*}(t)$ are the domestic and foreign $k$-period nominal interest rates, respectively.
} 
rate differences. The fractional exponent estimates are very similar for both tenors and are below the stationarity threshold of 0.5. The series for the Euroyen term premium differences exhibits intermediate memory (negative fractional exponents). This suggests that the term premium series in levels exhibits long memory with an estimated long-memory parameter around $0.85 .{ }^{4}$ This Euroyen term spread series is therefore nonstationary but mean reverting.

With the exception of the spot, forward, and stock returns series, none of the series we have examined are short-memory processes. The implications of the longmemory evidence can be seen in both the time and frequency domains. In the time domain, long memory is indicated by the fact that the series eventually exhibit positive dependence between distant observations. In the frequency domain, long memory is indicated by the fact that the spectral density becomes unbounded as the frequency approaches zero; the series has power at low frequencies.

\section{Conclusions}

We tested for stochastic long memory via the spectral regression and Gaussian semiparametric methods in a number of Japanese financial time series. Currency forward premia, Euroyen deposit rate changes, and the Euroyen term premium appear to be characterized by irregular cyclic fluctuations with long-term dependence. These series exhibit significant persistence but they are mean-reverting processes. The currency forward premia and Euroyen term premium series are nonstationary

\footnotetext{
4 Even though the evidence may not be very strong in support of long memory for the Euroyen term premia series, application of the Phillips-Perron (Phillips (1987), Phillips and Perron (1988)) and Kwiatkowski, Phillips, Schmidt and Shin (1992) tests suggest that neither an I(1) nor an I(0) process is an appropriate representation of the series dynamics, thus alluding to the presence of a fractional root in the series.
} 
processes. The martingale model appears to be appropriate for the spot and forward rates and stock price series.

The presence of long memory represents nonlinearity in the mean of the process and therefore suggests possibilities for constructing nonlinear econometric models for improved forecasting performance, especially over longer forecasting horizons. The nonlinear model construction suggested is that of an ARFIMA representation, which represents a flexible and parsimonious way to model both the short- and long- term dynamical properties of the series. Questions also arise as to the source of long memory in the Euroyen deposit-rate series. The discovery of long memory in these series may reflect the statistical property of fundamental factors underlying their behavior. It could also be the result of particular monetary policies or interventions performed by the monetary authorities. These questions await future research. 


\section{References}

Akella, S. R. and A. Patel, 1991, Are international real rates of interest cointegrated? Evidence from the recent floating exchange rate period, unpublished manuscript, University of Missouri.

Aydogan, K. and G. G. Booth, 1988, Are there long cycles in common stock returns?, Southern Economic Journal 55, 141-149.

Baillie, R., 1996, Long memory processes and fractional integration in econometrics, Journal of Econometrics 73, 5-59.

Baillie, R. and T. Bollerslev, 1994, The long memory of the forward premium, Journal of International Money and Finance 13, 565-571.

Barkoulas, J. T. and C. F. Baum, 1996, Long term dependence in stock returns, Economics Letters, 53, 253-259.

Barkoulas, J. T., W. C. Labys, and J. Onochie, 1997a, Long memory in futures prices, Financial Review, forthcoming.

Barkoulas, J. T., W. C. Labys, and J. Onochie, 1997b, Fractional dynamics in international commodity prices, Journal of Futures Markets 17, 161-189.

Booth, G. G., F. R. Kaen and P. E. Koveos, 1982, R/S analysis of foreign exchange markets under two international monetary regimes, Journal of Monetary Economics 10, 407-415.

Brenner, R. and K. Kroner, 1995, Arbitrage, cointegration, and testing the unbiasedness hypothesis in financial markets, Journal of Financial and Quantitative Analysis 30, 23-42.

Cheung, Y. W., 1993, Long memory in foreign-exchange rates, Journal of Business and Economic Statistics 11, 93-101.

Cheung, Y. and K. Lai, 1993, Do gold market returns have long memory? Financial Review 28, 181-202. 
Cheung, Y. and K. Lai, 1995, A search for long memory in international stock market returns, Journal of International Money and Finance 14, 597-615.

Cheung, Y. W., K. S. Lai and M. Lai, 1993, Are there long cycles in foreign stock returns? Journal of International Financial Markets, Institutions and Money 3, 33-47.

Crato, N., 1994, Some international evidence regarding the stochastic memory of stock returns, Applied Financial Economics 4, 33-39.

Fang, H., K. S. Lai and M. Lai, 1994, Fractal structure in currency futures prices, Journal of Futures Markets 14, 169-181.

Geweke J. and S. Porter-Hudak, 1983, The estimation and application of long memory time series models, Journal of Time Series Analysis 4, 221-238.

Granger, C. W. J. and R. Joyeux, 1980, An introduction to long-memory time series models and fractional differencing, Journal of Time Series Analysis 1, 15-39.

Greene, M. T. and B. D. Fielitz, 1977, Long-term dependence in common stock returns, Journal of Financial Economics 5, 339-349.

Helms, B. P., F. R. Kaen and R. E. Rosenman, 1984, Memory in commodity futures contracts, Journal of Futures Markets 4, 559-567.

Hosking, J. R. M., 1981, Fractional Differencing, Biometrika 68, 165-176.

Kwiatkowski, D., P.C.B. Phillips, P. Schmidt and Y. Shin, 1992, Testing the null hypothesis of stationarity against the alternative of a unit root: how sure are we that economic time series have a unit root? Journal of Econometrics 54, 159-178.

Lo, A. W., 1991, Long-term memory in stock market prices, Econometrica 59, 12791313.

Mandelbrot, B. B., 1971, When can a price be arbitraged efficiently? a limit to the validity of the random walk and martingale models, Review of Economics and Statistics 53, 225-236. 
Mandelbrot, B. B., 1977, Fractals: Form, Chance, and Dimension (Free Press, New York).

Phillips, P.C.B., 1987, Time series regression with a unit root. Econometrica 55, 277301.

Phillips, P.C.B. and P. Perron, 1988, Testing for a unit root in time series regression. Biometrika 75, 335-346.

Robinson, P., 1995a, Log-periodogram regression of time series with long range dependence, Annals of Statistics 13, 1048-1072.

Robinson, P., 1995b, Gaussian semiparametric estimation of long range dependence, Annals of Statistics 13, 1630-1661.

Yajima, Y., 1985, On the estimation of long memory time series models, Australian Journal of Statistics 27, 303-320. 
Table 1: Estimates of the Fractional Differencing Parameter $d$ for Japanese Spot and Forward Exchange Rates and Stock Prices

\begin{tabular}{|c|c|c|c|c|}
\hline \multirow[t]{2}{*}{ Series } & \multicolumn{2}{|c|}{ Spectral Regression Estimates } & \multicolumn{2}{|c|}{ Gaussian Semiparametric Estimates } \\
\hline & $d(0.50)$ & $d(0.55)$ & $d(0.50)$ & $d(0.55)$ \\
\hline \multicolumn{5}{|l|}{ Spot Exchange Rates } \\
\hline U.S. Dollar & $\begin{array}{c}0.063 \\
(0.522)\end{array}$ & $\begin{array}{c}0.122 \\
(1.168)\end{array}$ & $\begin{array}{c}0.027 \\
(0.314)\end{array}$ & $\begin{array}{c}0.085 \\
(1.190)\end{array}$ \\
\hline Canadian Dollar & $\begin{array}{c}-0.123 \\
(-0.996)\end{array}$ & $\begin{array}{c}0.036 \\
(0.321)\end{array}$ & $\begin{array}{c}0.091 \\
(1.061)\end{array}$ & $\begin{array}{l}0.146 \\
(2.044)^{* *}\end{array}$ \\
\hline Deutsche Mark & $\begin{array}{c}0.070 \\
(0.522)\end{array}$ & $\begin{array}{c}0.107 \\
(0.991)\end{array}$ & $\begin{array}{c}0.086 \\
(1.002)\end{array}$ & $\begin{array}{c}0.120 \\
(1.680)^{*}\end{array}$ \\
\hline British Pound & $\begin{array}{c}-0.057 \\
(-0.395)\end{array}$ & $\begin{array}{c}0.083 \\
(0.635)\end{array}$ & $\begin{array}{c}0.101 \\
(1.177)\end{array}$ & $\begin{array}{c}0.173 \\
(2.422)^{* *}\end{array}$ \\
\hline French Franc & $\begin{array}{c}0.172 \\
(1.583)\end{array}$ & $\begin{array}{c}0.187 \\
(2.078)^{* *}\end{array}$ & $\begin{array}{c}0.187 \\
(2.180)^{* *}\end{array}$ & $\begin{array}{c}0.193 \\
(2.702)^{* * *}\end{array}$ \\
\hline Swiss Franc & $\begin{array}{c}0.198 \\
(1.389)\end{array}$ & $\begin{array}{c}0.129 \\
(1.219)\end{array}$ & $\begin{array}{c}0.102 \\
(1.189)\end{array}$ & $\begin{array}{c}0.119 \\
(1.660)^{*}\end{array}$ \\
\hline Netherlands Guilder & $\begin{array}{c}0.043 \\
(0.328)\end{array}$ & $\begin{array}{c}0.123 \\
(1.121)\end{array}$ & $\begin{array}{c}0.066 \\
(0.769)\end{array}$ & $\begin{array}{c}0.144 \\
(2.016)^{* *}\end{array}$ \\
\hline Italian Lira & $\begin{array}{c}0.088 \\
(0.518)\end{array}$ & $\begin{array}{c}0.070 \\
(0.558)\end{array}$ & $\begin{array}{c}0.143 \\
(1.667)^{*}\end{array}$ & $\begin{array}{c}0.155 \\
(2.170)^{* *}\end{array}$ \\
\hline \multicolumn{5}{|c|}{ 3-Month Forward Rates } \\
\hline U.S. Dollar & $\begin{array}{c}0.054 \\
(0.419)\end{array}$ & $\begin{array}{c}0.094 \\
(0.936)\end{array}$ & $\begin{array}{c}0.026 \\
(0.303)\end{array}$ & $\begin{array}{c}0.097 \\
(1.358)\end{array}$ \\
\hline Canadian Dollar & $\begin{array}{c}-0.139 \\
(-1.120)\end{array}$ & $\begin{array}{c}0.023 \\
(0.195)\end{array}$ & $\begin{array}{c}0.085 \\
(0.991)\end{array}$ & $\begin{array}{c}0.146 \\
(2.044)^{* *}\end{array}$ \\
\hline Deutsche Mark & $\begin{array}{c}0.085 \\
(0.611)\end{array}$ & $\begin{array}{c}0.111 \\
(0.998)\end{array}$ & $\begin{array}{c}0.100 \\
(1.166)\end{array}$ & $\begin{array}{c}0.136 \\
(1.904)^{*}\end{array}$ \\
\hline British Pound & $\begin{array}{c}-0.045 \\
(-0.322)\end{array}$ & $\begin{array}{c}0.079 \\
(0.663)\end{array}$ & $\begin{array}{c}0.100 \\
(1.166)\end{array}$ & $\begin{array}{c}0.179 \\
(2.506)^{* *}\end{array}$ \\
\hline French Franc & $\begin{array}{c}0.186 \\
(1.719)^{*}\end{array}$ & $\begin{array}{c}0.196 \\
(2.291)^{* *}\end{array}$ & $\begin{array}{c}0.212 \\
(2.472)^{* *}\end{array}$ & $\begin{array}{c}0.225 \\
(3.150)^{* * *}\end{array}$ \\
\hline Swiss Franc & $\begin{array}{c}0.195 \\
(1.419)\end{array}$ & $\begin{array}{c}0.121 \\
(1.188)\end{array}$ & $\begin{array}{c}0.111 \\
(1.294)\end{array}$ & $\begin{array}{c}0.119 \\
(1.666)^{*}\end{array}$ \\
\hline Netherlands Guilder & $\begin{array}{c}0.057 \\
(0.432)\end{array}$ & $\begin{array}{c}0.123 \\
(1.114)\end{array}$ & $\begin{array}{c}0.080 \\
(0.932)\end{array}$ & $\begin{array}{c}0.151 \\
(2.114)^{* *}\end{array}$ \\
\hline
\end{tabular}


Italian Lira

0.068

(0.497)

0.163

(1.076)

Stock Price Index

(1.076)

0.074

(0.681)

0.089

(0.767)
0.141

$(1.644)^{*}$

0.032

(0.286)
0.152

$(2.128)^{* *}$

Notes: The data for the foreign exchange series cover the period 01/07/1974 to 01/27/1997 for a total of 1,204 weekly observations. The sample period spans 1960:1 to 1996:5 for the monthly Japanese stock price index. All series are in returns form (first differences of the logarithms of the original series). $d(0.50)$ and $d(0.55)$ give the $d$ estimates corresponding to estimation sample size $v=T^{0.50}$ and $v=T^{0.55}$, respectively. The $t$-statistics are given in parentheses. The superscripts $* * * * * *$ indicate statistical significance for the null hypothesis $d=0$ against the alternative $d \neq 0$ at the 1,5 , and 10 per cent levels, respectively. 
Table 2: Empirical Estimates of the Fractional Differencing Parameter $d$ of the Japanese Yen Forward Premia

\begin{tabular}{lcccc}
\hline \hline Series & \multicolumn{2}{c}{ Spectral Regression Estimates } & \multicolumn{2}{c}{ Gaussian Semiparametric Estimates } \\
\hline \hline U.S. Dollar & $d(0.50)$ & $d(0.55)$ & $d(0.50)$ & $d(0.55)$ \\
Canadian Dollar & -0.272 & -0.199 & -0.233 & -0.174 \\
& $(-2.692)^{* *}$ & $(-2.525)^{* *}$ & $(-2.717)^{* * *}$ & $(-2.436)^{* *}$ \\
Deutsche Mark & -0.207 & -0.158 & -0.209 & -0.157 \\
& $(-2.294)^{* *}$ & $(-2.211)^{* *}$ & $(-2.437)^{* *}$ & $(-2.198)^{* *}$ \\
British Pound & -0.402 & -0.356 & -0.360 & -0.301 \\
& $(-3.560)^{* * *}$ & $(-4.180)^{* * *}$ & $(-4.198)^{* * *}$ & $(-4.214)^{* * *}$ \\
French Franc & -0.160 & -0.220 & -0.203 & -0.208 \\
Swiss Franc & $(-1.134)$ & $(-2.140)^{* *}$ & $(-2.367)^{* *}$ & $(-2.912)^{* *}$ \\
Netherlands Guilder & -0.299 & -0.301 & -0.307 & -0.262 \\
& $(-2.479)^{* * * * *}$ & $(-3.538)^{* * *}$ & $(-3.580)^{* * *}$ & $(-3.668)^{* * *}$ \\
Italian Lira & -0.499 & -0.448 & -0.447 & -0.393 \\
& $(-4.488)^{* * *}$ & $(-5.486)^{* * *}$ & $(-5.218)^{* * *}$ & $(-5.502)^{* * *}$ \\
\hline \hline
\end{tabular}

Notes: The forward premium is given by $f(t, t+k)-s(t)$, where $f(t, t+k)$ is the logarithm of the forward rate at time $t$ of a forward contract with delivery date $t+k$, with $k$ corresponding to a 3-month period in our case, and $s(t)$ is the logarithm of the spot rate at time $t$. See notes in Table 1 for the data description. $d(0.50)$ and $d(0.55)$ give the $d$ estimates corresponding to estimation sample size $v=T^{0.50}$ and $v=T^{0.55}$, respectively. The $t$-statistics are given in parentheses. The superscripts $* * *,^{* *} *$ indicate statistical significance for the null hypothesis $d=0$ against the alternative $d \neq 0$ at the 1,5 , and 10 per cent levels, respectively. 
Table 3: Empirical Estimates of the Fractional Differencing Parameter $d$ of Euroyen Rates and the Euroyen Term Premium

\begin{tabular}{lcccc}
\hline \hline Series & \multicolumn{2}{c}{ Spectral Regression Estimates } & \multicolumn{2}{c}{ Gaussian Semiparametric Estimates } \\
\hline \hline 3-Month Euroyen & $d(0.50)$ & $d(0.55)$ & $d(0.50)$ & $d(0.55)$ \\
& 0.216 & 0.242 & 0.193 & 0.190 \\
& $(3.017)^{* * *}$ & $(3.815)^{* * *}$ & $(2.646)^{* * *}$ & $(3.179)^{* * *}$ \\
6-Month Euroyen & 0.271 & 0.261 & 0.199 & 0.180 \\
& $(2.782)^{* * *}$ & $(3.295)^{* * *}$ & $(2.728)^{* * *}$ & $(3.011)^{* * *}$ \\
Euroyen Term Premium & -0.174 & -0.130 & -0.142 & -0.090 \\
& $(-1.970)^{* *}$ & $(-1.853)^{*}$ & $(-1.947)^{*}$ & $(-1.505)$ \\
\hline \hline
\end{tabular}

Notes: The sample period spans 01/01/85 to 02/08/94 for the Euroyen series for a total of 2,300 daily observations. The term premium is the difference between the 6-month and the 3-month Euroyen rates. The fractional integration tests are applied to the first-differenced series. $d(0.50)$ and $d(0.55)$ give the $d$ estimates corresponding to estimation sample size $v=T^{0.50}$ and $v=T^{0.55}$, respectively. The $t$-statistics are given in parentheses. The superscripts ${ }^{* * *}, * * * *$ indicate statistical significance for the null hypothesis $d=0$ against the alternative $d \neq 0$ at the 1,5, and 10 per cent levels, respectively. 